UCRL-ID-128051

\title{
Electrical Resistance Tomography for Monitoring the Infiltration of Water into a Pavement Section
}

\author{
M. Buettner \\ B. Daily
}

A. Ramirez

July 3, 1997

This is an informal report intended primarily for internal or limited external distribution. The opinions and conclubiona stated are those of the author and may or may not be those of the Laboratory. 


\section{DISCLAIMER}

This document was prepared as an account of work sponsored by an agency of the United States Government. Neither the United States Government nor the University of California nor any of their employees, makes any warranty, express or implied, or assumes any legal liability or responsibility for the accuracy, completeness, or usefulness of any information, apparatus, product, or process disclosed, or represents that its use would not infringe privately owned rights. Reference herein to any specific commercial product, process, or service by trade name, trademark, manufacturer, or otherwise, does not necessarily constitute or imply its endorsement, recommendation, or favoring by the United States Government or the University of California. The views and opinions of authors expressed herein do not necessarily state or reflect those of the United States Government or the University of California, and shall not be used for advertising or product endorsement purposes.

This report has been reproduced directly from the best available copy.

Available to DOE and DOE contractors from the Office of Scientific and Technical Information

P.O. Box 62, Oak Ridge, TN 37831

Prices available from (615) 576-8401, FTS 626-8401

Available to the public from the

National Technical Information Service

U.S. Department of Commerce

5285 Port Royal Rd.,

Springfield, VA 22161 


\title{
Electrical Resistance Tomography \\ for Monitoring the Infiltration of \\ Water into a Pavement Section
}

\author{
Michael Buettner \\ Bill Daily \\ Abe Ramirez \\ LLNL
}

\begin{abstract}
Electrical resistance tomography (ERT) was used to follow the infiltration of water into a pavement section at the UC Berkeley Richmond Field Station. A volume of pavement $1 \mathrm{~m}$ square and 1.29 m deep was sampled by an ERT array consisting of electrodes in 9 drilled holes plus 8 surface electrodes. The data were collected using a computer-controlled data acquisition system capable of collecting a full data set in under 1 hour, allowing for nearly real-time sampling of the infiltration. The infiltration was conducted in two phases. During the first phase, water was introduced into the asphalt-concrete $(\mathrm{AC}$ ) layers at a slow rate of about $8 \mathrm{ml} / \mathrm{h}$ for a period of about 6 days. In the second phase, water was introduced into the asphalt-treated-permeable base (ATPB) layer at a more rapid rate of about $100 \mathrm{ml} / \mathrm{h}$ for about 2 days. The ERT images show that water introduced into the upper $\mathrm{AC}$ layers shows up as a decrease in resistivity which grows with time. The images also appear to show that when water moves into the layers below the ATPB, the resistivity increases; an unexpected result. There are some indications that the water moved laterally as well as down into the deeper ATPB and aggregate base. The images also show that when water is introduced directly into the ATPB layer, the water moves into the underlying materials much more quickly. Analysis of the data is incomplete but ongoing at this time.
\end{abstract}

\section{Background}

The work described in this report represents the continuation and completion of a contract between Lawrence Livermore National Laboratory (LLNL) and the California Department of Transportation (Caltrans) which began in November of 1994, and was terminated in June, 1995. A contract for the balance of the work was approved in November of 1996, and was to be completed by June 30 , 1997. 
The major objectives of this work are 1) to adapt and improve Electrical Resistance Tomography (ERT) imaging to the point where it can be used to map spatial moisture distribution and moisture movement in pavements, 2) to develop a prototype ERT acquisition and display system for use in a research environment, and 3) to identify specific applications for ERT in pavement engineering.

The work is broken down into the five tasks which follow.

Task 1) Improve Data Acquisition System

The principal goal is to improve the speed of the data acquisition system so that we can track moisture movement in pavements in nearly real time.

\section{Task 2) Improve Inversion Code}

The objective is to evaluate and improve an existing prototype of a fully 3-dimensional ERT inversion code.

\section{Task 3) Laboratory Measurements}

The objective is to make laboratory measurements of the electrical resistivity for the principal materials in the pavements section at the controlled infiltration experiment (see Task 4).

\section{Task 4) Controlled Infiltration Experiment}

The objective is to perform a simple, controlled water infiltration experiment. Water will be introduced into a pavement section at the U.C. Berkeley Richmond Field Station in a controlled manner and monitored with ERT imaging in several planes.

\section{Task 5 Develop Project Report}

\section{Introduction}

The presence of water in pavements has a major influence on design and performance of pavement structures during their design life. Current knowledge about the presence of water in pavement materials and how it moves around in response to seasonal and load variations are based upon a combination of theory, engineering judgment, and a few confirmatory measurements. Moreover there are problems associated with the sensors typically used to make moisture measurements such as electrical resistance moisture sensors (ERMS), and time domain reflectometry (TDR) probes. For example, each ERMS must be calibrated separately for the type of soil in which it is placed--an expensive proposition because it is labor-intensive. In addition moisture content is sensed only at a 
point or in small volume around the sensor necessitating a large number of sensors to achieve a reasonable sampling density. Emplacing large numbers of sensors is labor-intensive, expensive, and difficult in existing pavements which comprise nearly all of the highway network.

Electrical Resistance Tomography (ERT) is a method of imaging which allows one to gather information about the electrical resistivity distribution in planes whose boundaries are described by arrays of electrodes in boreholes or implanted on the surface. The collected data are "inverted" to obtain a resistivity picture which is analogous to the familiar images produced by Computed Axial Tomography (CAT) in medicine (Hounsfield, 1973), and which can be interpreted in terms of moisture distribution for many natural and man-made materials. ERT technology allows one to measure the electrical resistivity of materials in the plane between drill holes using electrodes located at the plane boundaries. This is in direct contrast to the information provided by ERMS and TDR sensors where the moisture content can be inferred only in the region immediately around the sensors.

ERT technology was developed originally for medical applications (Hounsfield, 1973), but has been extended over the years by many workers into other areas such as geophysics where it has been effectively used to monitor steam flow in environmental remediation (Ramirez et al, 1993), to monitor the infiltration of water into soils (Daily et al, 1992), to detect leaks from storage tanks and ponds (Daily, 1993), and, in a preliminary experiment, to show the infiltration of water into a pavement section (Kim and Nokes, 1993).

In this California Department of Transportation (Caltrans) study Kim and Nokes conclude that ERT can be used to study drained pavement structures after some improvements to the technology. To better understand water flow in the pavement system they recommend improvements to the data collection and analysis system. Specifically the data collection time should be decreased to better match the time scale of changes in the flow pattern in the pavement structure. In addition they suggest that the system be changed so that data can be collected in multiple planes simultaneously. Finally the current 2-dimensional image reconstruction code needs to be replaced with a 3dimensional version which better matches the spatial characteristics of water movement in pavements.

With a fast data collection system and enhanced computer codes for ERT image reconstruction, ERT technology eventually should be applicable in numerous areas of pavement study such as visualizing water flow in pavement systems, pumping mechanisms, and traffic effects on water movement in pavement structures. 


\section{Electrical Resistance Tomography (ERT); concept and theory}

To image the resistivity distribution between two boreholes, several electrodes are placed in each hole; each electrode in electrical contact with the formation (see Figure 1). Two electrodes are driven by a known current and the resulting voltage difference is measured between other pairs of electrodes. Each voltage to current ratio is called a transfer resistance. Then, a known current is applied between two other electrodes and voltage differences are measured again using electrode pairs which are not being used for the source current. This process is repeated until all the linearly independent combinations are measured. For $n$ electrodes there are $n(n-3) / 2$ independent transfer resistances. The measurements which we have described for a cross borehole survey are similar to those used in the conventional surface dipole-dipole resistivity survey [Schlumberger, 1920].

The goal is to calculate the distribution of resistivity in the vicinity of the boreholes given the measured transfer resistances. This problem, although highly nonlinear because the current paths are dependent on the resistivity distribution, has been studied by many people. For example, Dines and Lytle [1981] used a circuit analysis approach to generate estimates of the conductivity using an iterative process on network equations that are linearized in the unknown conductance variables. Other early approaches met with varying degrees of success (e.g., Henderson and Webster [1978], Pelton et al. [1978], Nariida and Vozoof [1984], Tripp et al., [1984], Kohn and Vogelius [1987], Wexler et al. [1985], Brown et al. [1985], Isaacson [1986], Yorkey [1986], Yorkey et al., [1987]). Recent work by Berryman and Kohn [1990] shows that variational constraints can be used to stabilize such inversions.

\section{Forward solution}

The forward solution to Poisson's equation uses the finite elements method (FEM) to compute electrical potential response of a two dimensional earth due to a three-dimensional source. To avoid the difficulty of numerically solving a three dimensional problem, Poisson's equation is formulated in wavenumber domain via Fourier transformation in the strike direction. The governing equation is [Hohmann, 1988]

$$
\frac{\partial}{\partial x}\left(\sigma \frac{\partial V}{\partial x}\right)+\frac{\partial}{\partial z}\left(\sigma \frac{\partial V}{\partial z}\right)-\lambda^{2} \sigma V=-I \delta(x) \delta(z)
$$


where $V$ is potential in Fourier transform domain, $\sigma$ is conductivity, $\lambda$ is the Fourier transform variable, $I$ is the source current, and $\delta(x)$ is the delta function. The two dimensional FEM algorithm discussed here is based on the theory described by Huebner and Thorton [1982] and the implementation follows that described by Wannamaker et al. [1987] for modeling two dimensional magnetotelluric data. Using the FEM method, potentials are calculated for a discrete number of transform variables at the nodes of a mesh of quadrilateral elements. The potentials are then inverse transformed back into Cartesian domain using the method described by LaBrecque [1989].

\section{Numerical Inversion}

The inversion method uses the modified Marquardt algorithm discussed in Chapter 5 of Bard [1974] to jointly solve the non-linear equation

$$
\underline{\mathbf{W}}=\underline{\mathbf{W}} \cdot \mathbf{F}(\mathbf{P}),
$$

and the equation

$$
\mathbf{P}^{\mathbf{T}} \underline{\mathbf{R}} \mathbf{P}=0
$$

where $\mathbf{D}$ is the vector of known data values, $\underline{\mathbf{W}}$ is a weighting matrix, $\mathbf{P}$ is the vector of unknown parameters; $\mathbf{F}(\mathbf{P})$ is the forward solution and $\underline{\mathbf{R}}$ is the roughness matrix which is a numerical approximation to the Laplacian operator [Sasaki, 1990]. To solve these equations jointly, the algorithm minimizes

$$
\chi^{2}+\operatorname{cL}(\mathbf{P})=0
$$

where $\mathrm{c}$ is a constant and $\chi^{2}$ is the Chi-squared statistic which is given by

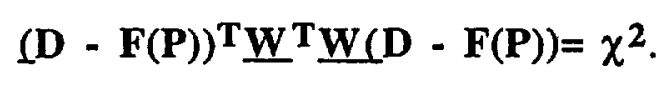

Ideally the inverse algorithm would find the maximum value of $\mathrm{c}$ for which $\chi^{2}$ is equal to some known, a priori value. The constant, $c$, was determined by trial and error by calculating an inverse model with an a priori value of $\mathrm{c}$ then adjusting $\mathrm{c}$ if necessary to achieve the correct value of $\chi^{2}$.

\section{The infiltration experiment}


The infiltration experiment, Task 4, took place at the UC Berkeley Richmond Field Station, B-280. This is the same facility that is currently being used for Accelerated Pavement Testing Program, a joint project between Caltrans, the University of California, Berkeley, and the South African Council on Scientific and Industrial Research (CSIR). In this program a Heavy Vehicle Simulator, HVS, is being used to do accelerated testing of pavement sections. This project was able to use a small pavement section in B-280 which will not be used with the HVS.

\section{Layout and installation}

The test pavement section consists of an asphalt-concrete (AC) overlay, underlain by two densegrade asphalt concrete (DGAC) layers, underlain by a layer of asphalt-treated permeable base (ATPB), aggregate base, aggregate sub-base, and then native soil. The cross section is shown in Figure 2.

An ERT electrode array was installed in the test section in early May, 1997. The ERT array is shown schematically in Figure 3. It consists of ERT arrays in 9 numbered boreholes which define the corners of an outer box, the corners of an inner box, and the center of both boxes. In addition there are 8 surface electrodes. The outer box is $1 \mathrm{~m}$ (39.4 in.) on a side, and the inner box is $0.333 \mathrm{~m}$ (13.1 in.) on a side.

The arrays in boreholes $1,4,13,16$, and 17 define the outer box (and center), and have 13 electrodes each. The electrodes are spaced $10.16 \mathrm{~cm}$ apart (4 in.) with the uppermost electrode placed $7.62 \mathrm{~cm}(3 \mathrm{in}$.) from the pavement surface. The arrays in boreholes $6,7,10$, and 11 define the corners of the inner box, and have 8 electrodes each. The electrodes are spaced $10.16 \mathrm{~cm} \mathrm{(4}$ in.) apart with the uppermost electrode placed $7.62 \mathrm{~cm} \mathrm{(3} \mathrm{in.)} \mathrm{from} \mathrm{the} \mathrm{pavement} \mathrm{surface.} \mathrm{The}$ surface electrodes are in boreholes $2,3,5,8,9,12,14,15$, and are placed $7.62 \mathrm{~cm}(3 \mathrm{in}$.) from the surface.

This layout of ERT electrode arrays was designed to provide good coverage of the volume during the infiltration. A complete data set for this array consists of the vertical planes for the sides of the outer box, (planes 4-1, 13-1, 4-16, 13-16), vertical diagonals for the outer box (1-17, 4-17, 1317, 16-17), vertical planes for the sides of the inner box $(7-6,7-11,10-6,10-11)$, vertical diagonals for the inner box (6-17, 7-17, 10-17, 11-17), and the surface array consisting of the uppermost electrodes in holes 1-16. The full data set takes approximately $6.5 \mathrm{~h}$ to collect and consists of 6656 data values. 
The electrode arrays are constructed very simply from pieces of stainless steel screen wrapped around a plastic pipe and secured to the pipe with PVC tape as shown in Figure 4. A wire for each electrode runs along the pipe to the surface and is terminated with a banana-style plug for connection to the measurement system. The electrode is connected electrically to the pavement or soil by a surrounding layer of cement grout. The three upper electrodes in each hole are isolated from each other by a plug of epoxy so that these electrodes are not directly shorted to each other by a continuous layer of conductive grout in the highly-resistive upper layers of the pavement section. The design is such that a small amount of water may be added from the inside of the pipe through small holes to wet the grout around the electrode if necessary which reduces the contact resistance to the pavement materials or soil.

Four holes were drilled into the pavement section to allow for water infiltration. The locations are shown in plan view in Figure 5. Hole A was $3.81 \mathrm{~cm}$ (1.5 in) deep and terminated in the AC overlay. Hole B was $10.2 \mathrm{~cm}$ (4 in) deep, and terminated in the first DGAC layer. Hole C was $17.1 \mathrm{~cm}(6.73 \mathrm{in})$ deep and terminated in the second DGAC layer. Finally, hole D was $24.1 \mathrm{~cm}$ (9.49 in) deep and terminated in the ATPB layer. This arrangement was chosen to allow for infiltration into each of the four pavements layers separately.

\section{The experiment}

The infiltration experiment began on May 29, 1997. Prior to May 29, full sets of background data were collected. These background data are used as a reference for comparisons to data collected during the infiltration.

The experiment consisted of water infiltration in two phases. During phase 1, a slow infiltration into the upper, relatively non-permeable pavement layers was desired. In contrast, during phase 2 , water was to be introduced at a higher rate into the more permeable-ATPB layer.

Phase 1 began by filling hole A with tap water to the top, and collecting ERT data while observing the rate of infiltration. In this case we observed no drop in the water level, and so decided to move to hole B. Water was added to hole B, and more ERT data were collected during observation. Again the water level did not fall. Water was now added to fill hole $\mathrm{C}$, and data were collected as before. This time the water level dropped at a rate of about $7 \mathrm{ml} / \mathrm{h}$. This rate was judged acceptable, and the water remaining in holes $\mathrm{A}$ and $\mathrm{B}$ was vacuumed out. The slow and steady infiltration into hole $C$ continued from May 29 through the morning of June 4. Data were collected 
periodically and records were kept of the quantity of water added to hole $\mathrm{C}$. The time history of the water infiltrated into hole $\mathrm{C}$ is plotted in Figure 6.

Phase 2 began on the morning of June 4, when water was introduced into hole D. We dripped water from a reservoir into the hole through the afternoon of June 6 . The time history of the water infiltrated into hole D is plotted in Figure 7. In this case the rate was not constant, and the average was about $102 \mathrm{ml} / \mathrm{h}$. We noted that the infiltration rate was controlled by the permeability of the ATPB layer since there was always some standing water in the bottom of the hole.

A block diagram of the ERT data collection system is shown in Figure 8. A Macintosh PowerBook computer controls the system, and collects and stores the data. The computer sets switches in the MX-30 multiplexer which selects a pair of electrodes where current is injected. In the same manner the switches are set to select other electrode pairs for the electrical potential measurements. The excitation current is supplied by the ZT-30 transmitter and HP power supply. The electrical potential measurements are made by the GDP-32 receiver, and the data are transferred via a serial cable to the computer.

A photograph of the data acquisition system as described above is shown in Figure 9. At the Richmond Field Station site, the system was deployed in a small rental truck for convenience.

\section{Results and discussion}

We begin by discussing ERT images from the inner box. Figure 10 shows a $3 \mathrm{~d}$ background resistivity image. As expected, there is a resistive upper layer corresponding to the $\mathrm{AC}$ layers and the ATPB. There is a sharp transition between the ATPB and the aggregate base, and the underlying materials are much less resistive. There is no one best way to display the $3 \mathrm{~d}$ nature of the resistivity distribution, so we have chosen to show several vertical planes and a horizontal plane to help visualize the resistivity distribution in the volume. Note that there are artifacts (features unrelated to the pavement structure) at the corners and center of the image. They are thought to be related to electrode effects near the boreholes.

The simplest way to visualize and discuss the ERT images from the infiltration is to look at the time history of the images for the various planes. This time history is presented in Figures 11 and 12. Let us consider the outer planes first. That is, we shall discuss the planes 10-11, 7-6, 10-6, and 711 which appear in Figure 11. We begin with 7-6, and 10-6 since those are the planes closest to the infiltration holes C and D. The sequence shows images from May 29, 30, 31, and June 1, 4, 
5, and 6. No data were collected on June 2 and 3. Each image in the sequence represents a comparison to the baseline case of May 28, and the results are presented as resistivity ratios according to the color bar. For example, any pixel at the extreme red end of the color bar has a resistivity value of 1.4 times that of the baseline case (resistivity increase), and any pixel at the extreme violet end of the color bar has a resistivity value of 0.4 times that of the baseline case (resistivity decrease). Also any pixel having the middle green color has a resistivity value of 1.0 times that of the baseline case which represents no change. Each image shows the region between the deepest electrode at $78.7 \mathrm{~cm}$ ( $31 \mathrm{in})$ and the uppermost electrode at $7.62 \mathrm{~cm}(3 \mathrm{in})$.

Starting the analysis with plane $7-6$, resistivity begins to decrease in the upper layers during the first day of the infiltration on May 29. This result is expected because the introduction of water into a dry, porous, resistive material will allow for ionic conduction. As more water infiltrates, the resistivity of the upper layers decreases still further on May 30 and 31, decreases a little on June 1, then shows a steady decrease through the end of the experiment on June 6. Note however, that a resistivity increase is beginning to develop deeper down between about $17.8 \mathrm{~cm}$ and $35.6 \mathrm{~cm}(7$ in to $14 \mathrm{in}$ ) from the pavement surface. The resistivity in this region increases further on May 31 , diminishes slightly on June 1, then grows through June 6. Also beginning on May 30, one sees a small resistivity decrease in the area $7.62 \mathrm{~cm}$ to $15.2 \mathrm{~cm}$ ( 3 in to 6 in) from the bottom of hole 6 which grows through June 6 .

As indicated above, the resistivity decreases in the resistive upper layers are quite reasonable since the infiltration of progressively larger amounts of water will allow for increasing ionic conduction. In addition, the resistivity decrease early on (May 30 to June 1) appears to the left of center corresponding to the projection of hole C onto the plane 7-6. Starting on June 4, when water is introduced into hole $D$, the decreases now show up to the right of center corresponding to the projection of hole $\mathrm{D}$ onto the plane 7-6.

The apparent resistivity increase between $17.8 \mathrm{~cm}$ and $35.6 \mathrm{~cm}$ (7 in and $14 \mathrm{in})$ is more difficult to explain. The initial expectation was that resistivity would decrease everywhere water had infiltrated. Two pieces of evidence suggest that these resistivity increases may be valid. The first is the monotonically increasing nature of the resistivity anomaly as can be seen in the sequence of images for plane 7-6 (and as noted later for plane 10-6). Natural processes tend to behave in this manner, as contrasted to anomalies introduced by noisy data or artifacts from the inversion algorithm. The second is that the raw data reveal resistivity increases in the same region with time. Thus stepping back one level from the image to the raw data shows the same trend. At the time of 
writing, additional data processing and analysis continues. We need to confirm that the unexpected resistivity increases observed are indeed valid.

The observed resistivity increases are unexpected, and not fully understood at this time. One possible explanation for a resistivity increase with infiltrating water is that the infiltrating water changes the chemistry of the conducting double layer in the ATPB and aggregate base.

Continuing with the analysis, let us now investigate plane 10-6. There is essentially no change in resistivity until June 4, when phase 2 of the infiltration begins. Prior to June 4, water infiltrated into hole $\mathrm{C}$ which is well out of the plane. Thus one might expect very little change. On June 4, just after the start of phase 2, one can see subtle changes at depths of about $30.5 \mathrm{~cm}$ to $45.8 \mathrm{~cm}$ (12 in to $18 \mathrm{in}$ ), or just below the ATPB layer. This indicates that the water introduced into hole D, which penetrates into the ATPB layer, gets into the aggregate base quickly. One June 5 and 6 the resistivity anomaly between $30.5 \mathrm{~cm}$ to $45.8 \mathrm{~cm}$ (12 in to $18 \mathrm{in}$ ) grows very quickly, and there is even some indication in the image of June 5 that the water has gone all the way to the bottom of the image at a depth of $78.7 \mathrm{~cm}$ (31 in).

Plane 7-11 shows no changes until May 31 when a resistivity decrease shows up to the left of center corresponding to the projection of hole $\mathrm{C}$ onto the plane 7-11. There also appears to be a slight increase at depths between $33.0 \mathrm{~cm}$ and $63.5 \mathrm{~cm}$ (13 in and $25 \mathrm{in}$ ). This increase is consistent through June 6 . The resistivity decrease in the upper layers appears to diminish after June 1 consistent with phase 2 where water infiltrates into hole D which is out of the plane.

Plane 10-11 shows resistivity decreases in the upper layers near hole 10 starting on May 31. A resistivity increase at depth is readily apparent on June 5 and 6 suggesting that water from hole D may be draining toward plane 10-11.

We shall now investigate the diagonal planes, 10-7 and 11-6 which appear in Figure 12.- The image of plane 10-7 is produced from data collected for planes 10-17, and 7-17 which are combined and then inverted. Likewise the image of plane 11-6 is produced from data collected for planes 11-17, and 6-17 which are combined and then inverted.

Plane 10-7 contains hole $\mathrm{C}$ and very clearly shows decreased resistivity at the location of hole $\mathrm{C}$ on May 31. One June 4, the resistivity increase between $27.9 \mathrm{~cm}$ and $38.1 \mathrm{~cm}$ (11 in and 15 in) indicates that water has gone below the ATPB layer; probably from hole C. On June 5 and 6 , this increase as depth diminishes consistent with hole $D$, the new source of water, now being out of the 
plane. Note also that the resistivity decrease in the upper layers moves toward the center of the plane on June 5 and 6 , also consistent with the new water source.

Plane 11-6 shows little change until May 31 when there is a slight decrease near hole 6. It is not clear why this should be in view of the infiltration source, hole $\mathrm{C}$, being far from the plane. Note that the image of plane 7-6 shows similar behavior near hole 6 . On June 4 , and thereafter, there is a resistivity decrease at depth below hole $D$, the water source, which is now in the plane.

What overall conclusions may be drawn from this set of images? As water is introduced into the upper resistive layers from a source like hole $\mathrm{C}$, the resistivity of these layers appears to decrease. This is consistent with the onset of ionic conduction with the introduction of mobile ions from the water, its ability to dissolve salts in the pavement materials, and double-layer conduction. This resistivity decrease seems to spread laterally in many cases.

Furthermore, if one accepts that water penetrating the ATPB layer and aggregate base can raise the resistivity, it is apparent that water can penetrate the upper AC layers and get into the ATPB layer and the aggregate base quickly. Water gets into the aggregate base even more quickly when it is introduced into the ATPB layer directly.

\section{Recommendations}

This work is a major improvement over the previous work at Riego Road. The pavement section was sampled much more densely which improved the spatial coverage. In addition, the higher data acquisition speed allowed for nearly real-time sampling of the process. Specifically, data for each of the inner planes was collected in about 5.5 minutes compared to about 45 minutes at Riego Road. Thus a full data set for the inner box could be collected in less than one hour. Finally, the data quality and the resulting images were much improved over the Riego Road data. This is possible because the current system has much-improved sensitivity and dynamic range which allows us to collect high-quality data even in high resistivity materials like the AC and ATPB layers.

Were this work to be extended, some improvements could be made. First the spatial resolution could be improved by having electrodes more closely spaced, and by decreasing the diameter of the

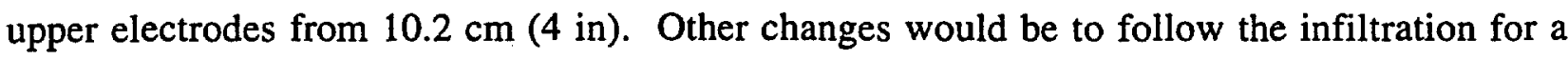
longer time period, and to investigate the effects of using more conductive water. 
As alluded to previously, analysis of the data continues; especially for the planes of the "outer box". Additional work in the lab, and at Richmond Field Station could be done to confirm the observed resistivity increases in the raw data and images.

\section{Acknowledgment}

The authors wish to thank personnel from Caltrans and the University of California Richmond Field Station who helped to make this work possible. Bill Nokes, Phil Stolarski, Ok-Kee Kim, and Jeff Pizzi from Caltrans merit kudos for their dogged determination in securing the funding for the work. John Harvey, Eddie Diaz and many others from the Richmond Field Station were also a great help.

Work performed under the auspices of the U.S. Department of Energy by the Lawrence Livermore National Laboratory under Contract W-7405-ENG-48.

\section{References}

Bard, Y., Nonlinear parameter estimation, Academic Press Inc., 111-113, 1974.

Berryman, J. G. and R. V. Kohn, Variational Constraints for ElectricalImpecanceTomography,Phys. Rev. Letts., 65 , 325-328, 1990.

Brown, B. H., D. C. Barber and A. D. Seagar, Applied Potential Tomography: Possible Clinical Applications, Clin. Phys. Physiol. Meas., 6, 109-121,1985.

Daily, W. and E. Owen, Cross Borehole Resistivity Tomography, Geophys., 56, 1228-1235, 1991.

Daily, W. D., W. Lin and T. Buscheck, "Hydrological Properties of Topopah Spring Tuff -Laboratory Measurements," J. Geophysical Res., 92, 7854-7864, 1987.

Daily, W., A. Ramirez, D. La Brecque, and J. Nitao, "Electrical Resistivity Tomography of Vadose Water Movement," prepared for submission to J. Water Resources Research, 1991.

Daily, W., A. Ramirez, D. LaBrecque and J. Nitao, Electrical Resistivity

Tomography of Vadose Water Movement, Water Resources Research, Vol 28, 1429-1442, 1992.

Daily, W. D., Lawrence Livermore National Laboratory, private communication, 1993.

Dines, K. A. and R. J. Lytle, Analysis of electrical conductivity imaging, Geophysics, Vol. 46, No. 7, Jul., 1025-1036, 1981.

Henderson, R. and J. Webster, An Impedance Camera for Spatially Specific Measurements of the Thorax, IEEE Trans. Biomed. Eng. BME-25, 250, 1978. 
Hohmann, G. W., Numerical Modeling for electromagnetic methods in geophysics, in Nabighian, M. N., Ed., Electromagnetic methods in geophysics, 1, Soc. Expl. Geophys., Invest. in Geophys., no. 3, 313-363, 1988.

Hounsfield, G. N., Method and Apparatus for Measuring X or Gamma Radiation Absorption or Transmission at Plural Angles and Analyzing the Data, US Patent 3.778.614, Dec. 11, 1973.

Huebner, K. H., and Thornton, E. A., The finite element method for engineers:, John Wiley, 1982.

Isaacson, D., Distinguishability of Conductivities by Electric Current Computed Tomography, IEEE Trans. Medical Imaging, Vol. MI-5, 91-95, 1986.

Kim, Ok-Kee, W. Nokes, B. Cramer, M. Buettner, and W. Daily, "Moisture Content Measurement of Pavement Section by Using ERT and Nuclear Gauge-Phase I", California Department of Transportation, 1992.

Kim, OK-Kee, and William A. Nokes, "Evaluation of Conductive Backfill Materials for Electrical Resistance Tomography", Final Report No. 65324-638041-33153, California State Transportation Department, Sacramento, CA, September, 1993.

Kohn, R. V. and M. Vogelius, Relaxation of a variational method for resistance computed tomography, Comm. Pure and Applied Math., XL, 745-777, 1987.

LaBrecque, D. J., Cross-borehole resistivity modeling and model fitting: Ph.D. thesis, Univ. of Utah, 1989.

Nariida, C. S. and K. Vozoff, Two-Dimensional DC Resistivity Inversion for Dipole-Dipole Data, IEEE Trans. on Geoscience and Remote Sensing, Vol. GE-22, 21-28, 1984.

Pelton, W. H., L. Rijo and C. M. Smith, Jr., Inversion of Two-Dimensional Resistivity and Induced-Polarizaion Data, Geophysics, 43, no. 4, 788-803, 1978.

Ramirez, A., W. Daily, D. LaBrecque, E. Owen and D. Chesnut, Monitoring an Underground Steam Injection Process Using Electrical Resistance Tomography,

Water Resources Research, Vol 29, no 1, 73-88, 1993.

Sasaki, Y., Model studies of resistivity tomography using boreholes, presented at the Soc. Expl. Geophys. Internat. Symp. on Borehole Geophysics: Petroleum, Hydrogeology, Mining and

- Engineering Applications, 1990.

Schlumberger, C., Etude de la prospection electrique du sous-sol, Paris, Gauthiers-Villars, 1920.

Tripp, A. C., G. W. Hohmann and C. M. Swift Jr., Two Dimensional Resistivity Inversion, Geophysics, 49, 1708-1717, 1984.

Wannamaker, P. E., J. A. Stodt, and L. Rijo, PW2D Finite Element Program for Solution of Magnetotelluric Responses of Two-Dimensional Earth Resistivity Structure, DOE/SAN/1219613, Univ. of Utah Research Institute, Earth Science Laboratory report ESL-158, pp. 40, 1987.

Wexler, A., B. Fry and M. R. Neuman, Impedance-computed tomography algorithm and system, Appl. Optics, 24, 3985-92, 1985. 
Yorkey, T. J., Comparing reconstruction methods for electrical resistance tomography, Ph.D. Thesis, University of Wisconsin, Madison, 1986.

Yorkey, T. J., J. G. Webster and W. J Tompkins, Comparing Reconstruction Algorithms for Electrical Impedance Tomography, IEEE Trans. Biomed. Eng., BME-34, 843-852, 1987. 


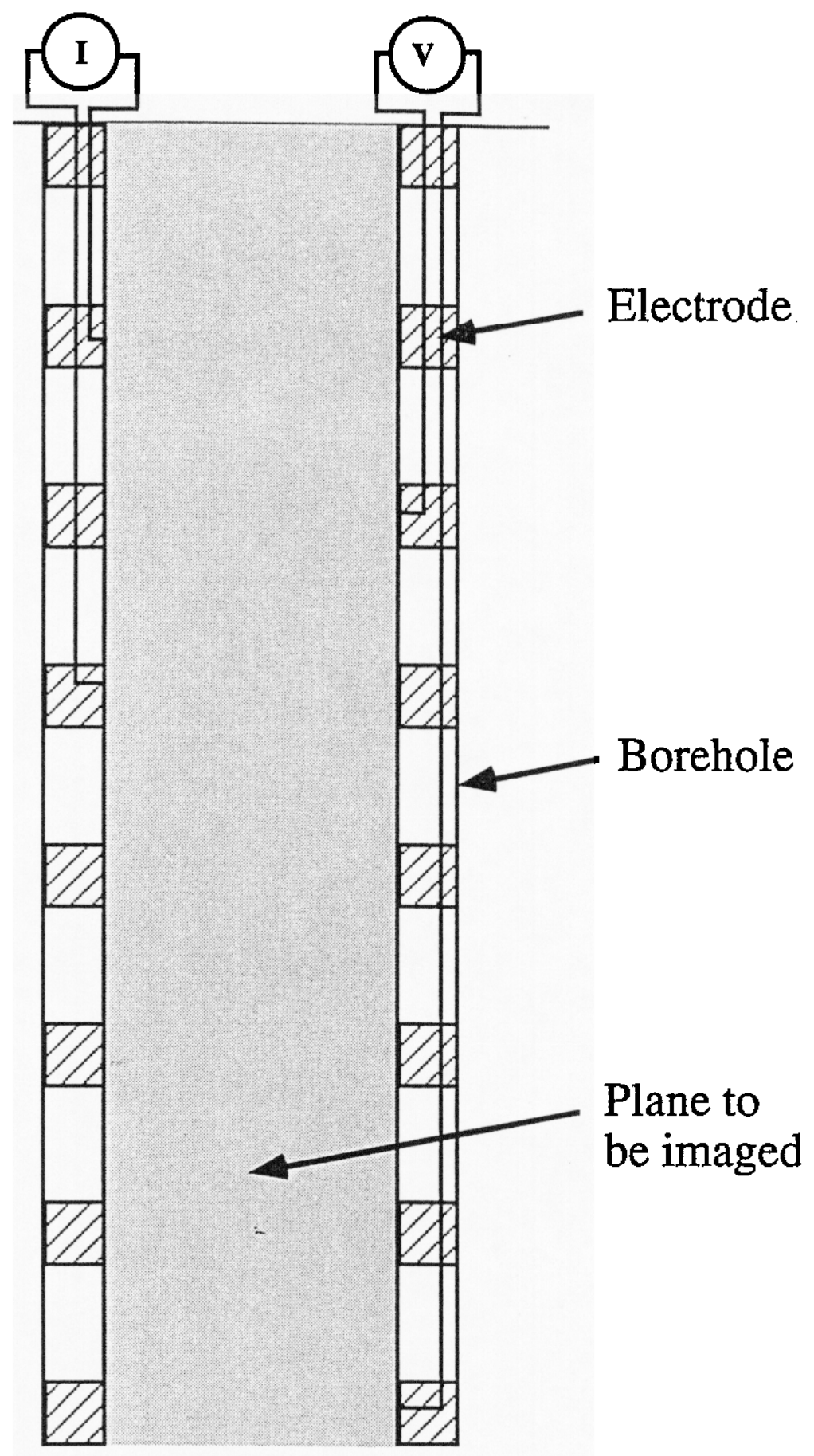

Figure 1. Schematic of resistivity measurements made between two boreholes. Electrodes in each borehole make electrical contact with the formation. 


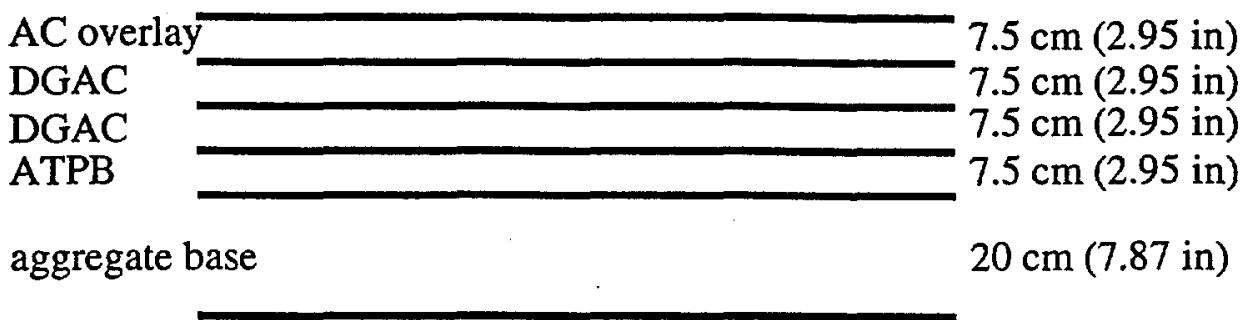

aggregate sub-base

$140 \mathrm{~cm}(55.1 \mathrm{in})$

native soil

Figure 2. The pavement cross section at Richmond Field Station 


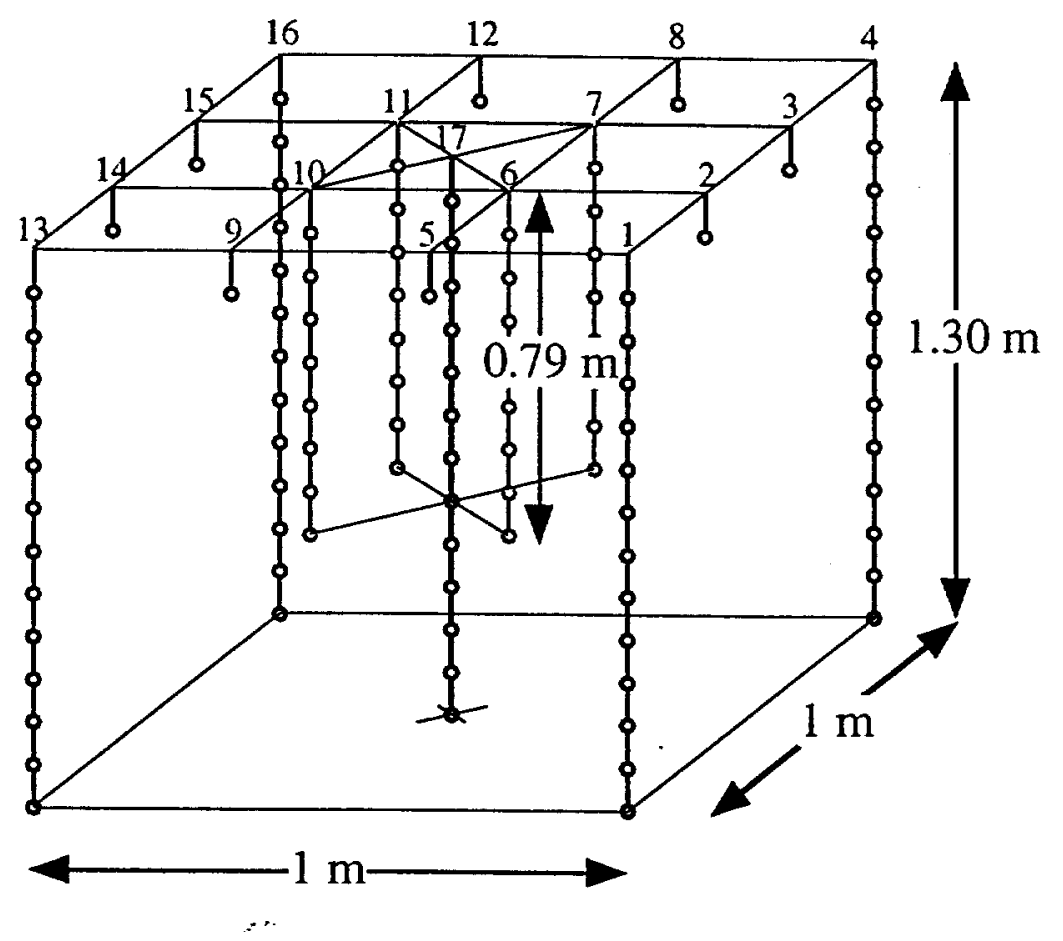

Figure 3. The layout of ERT arrays at Richmond Field Station 


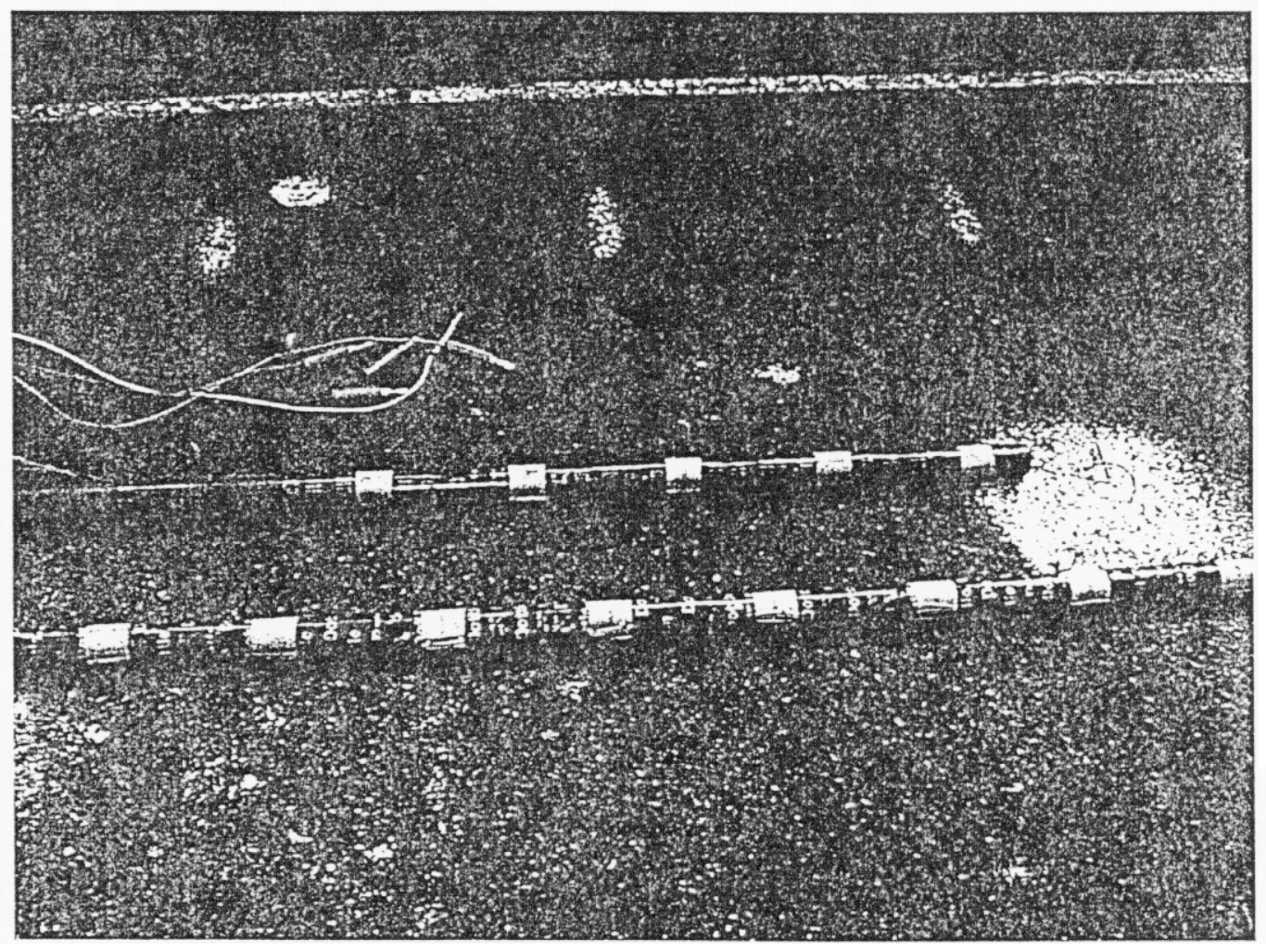

Figure 4. Examples of 2 ERT arrays for the Richmond Field Station 


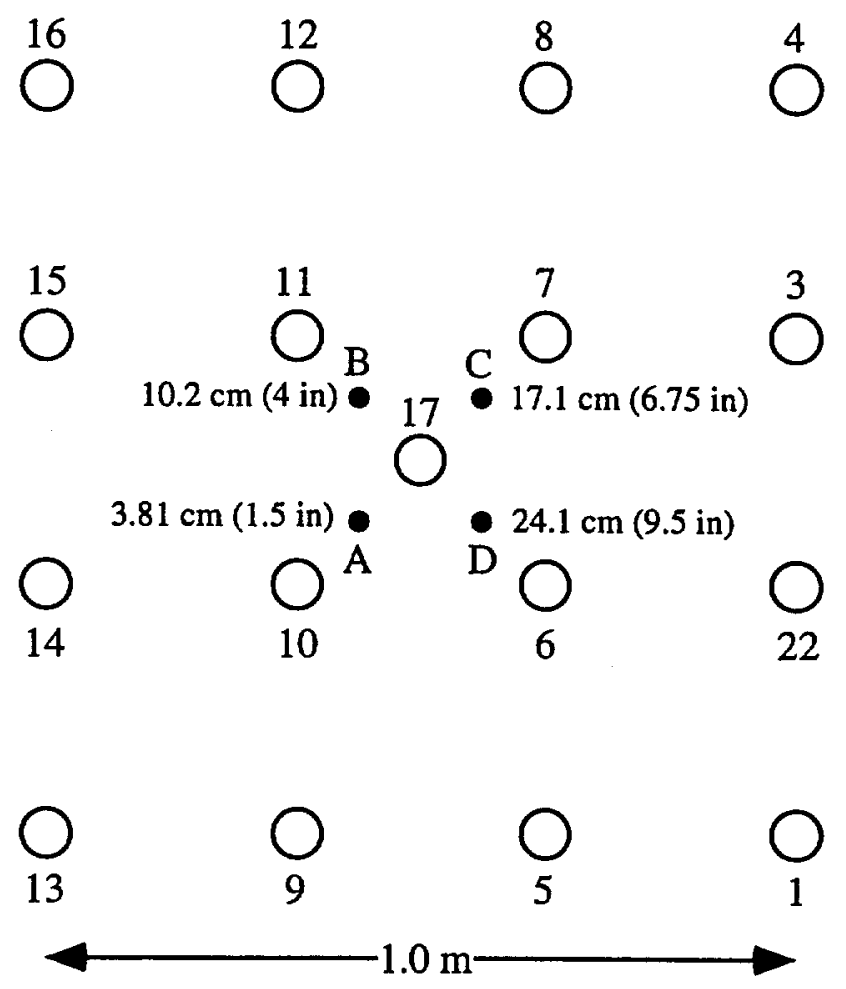

Figure 5. Plan view of the ERT array and the infiltration holes A, B, C, and D 


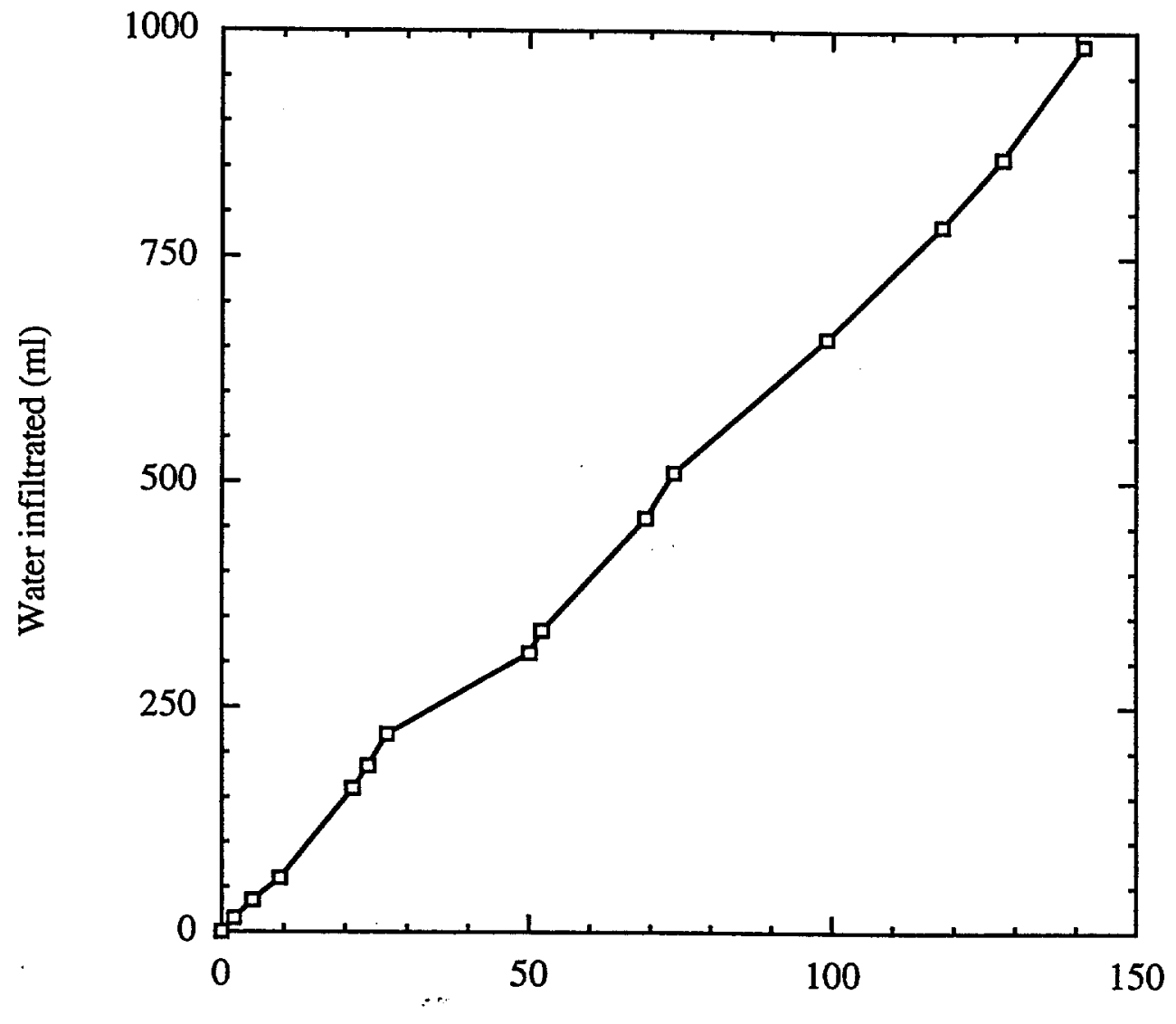

Time (h)

Figure 6. Quantity of water infiltrated into pavement section during phase 1 of the experiment at Richmond Field Station 


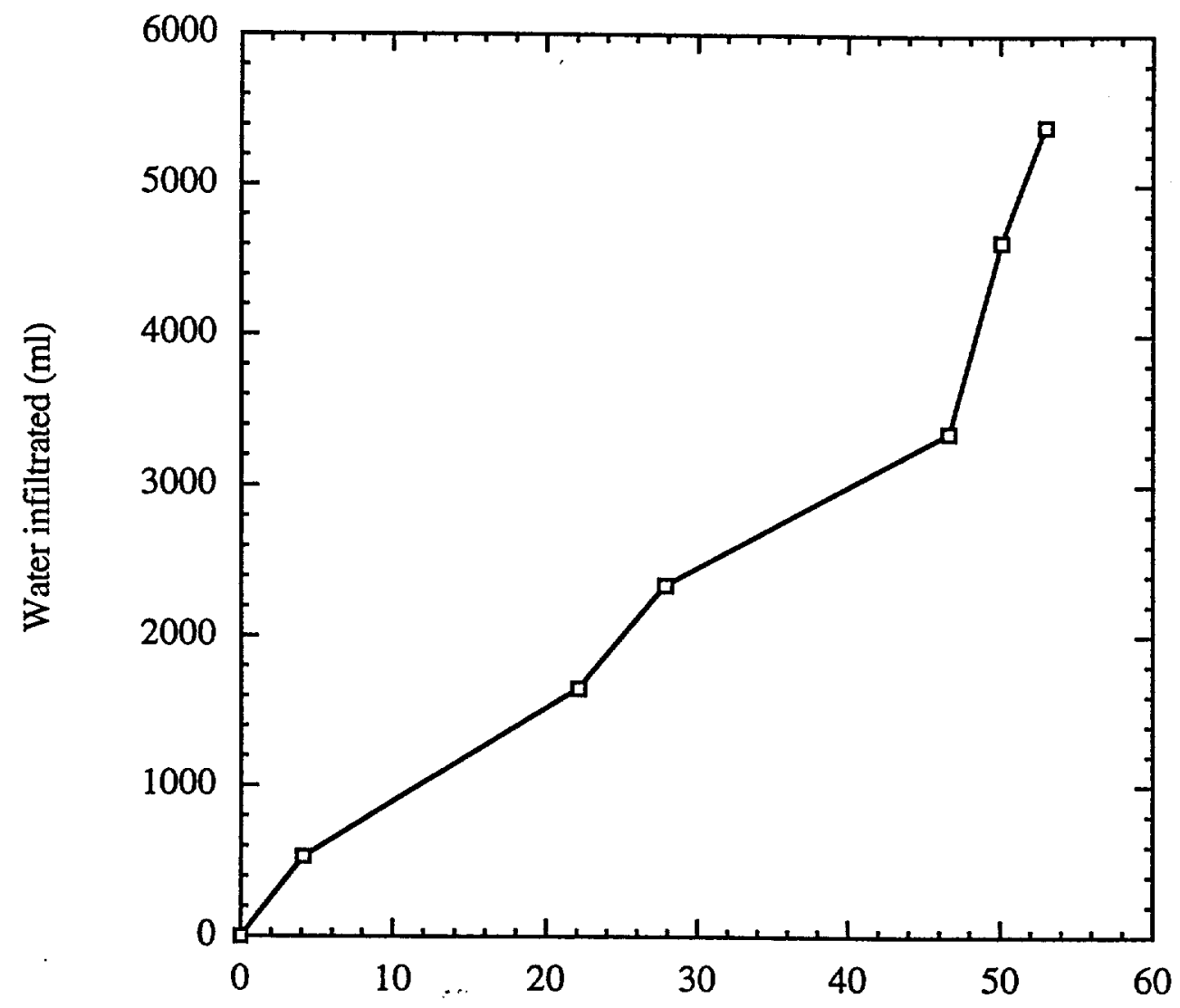

Time (h)

Figure 7. Quantity of water infiltrated into pavement section during phase 2 of the experiment at Richmond Field Station 


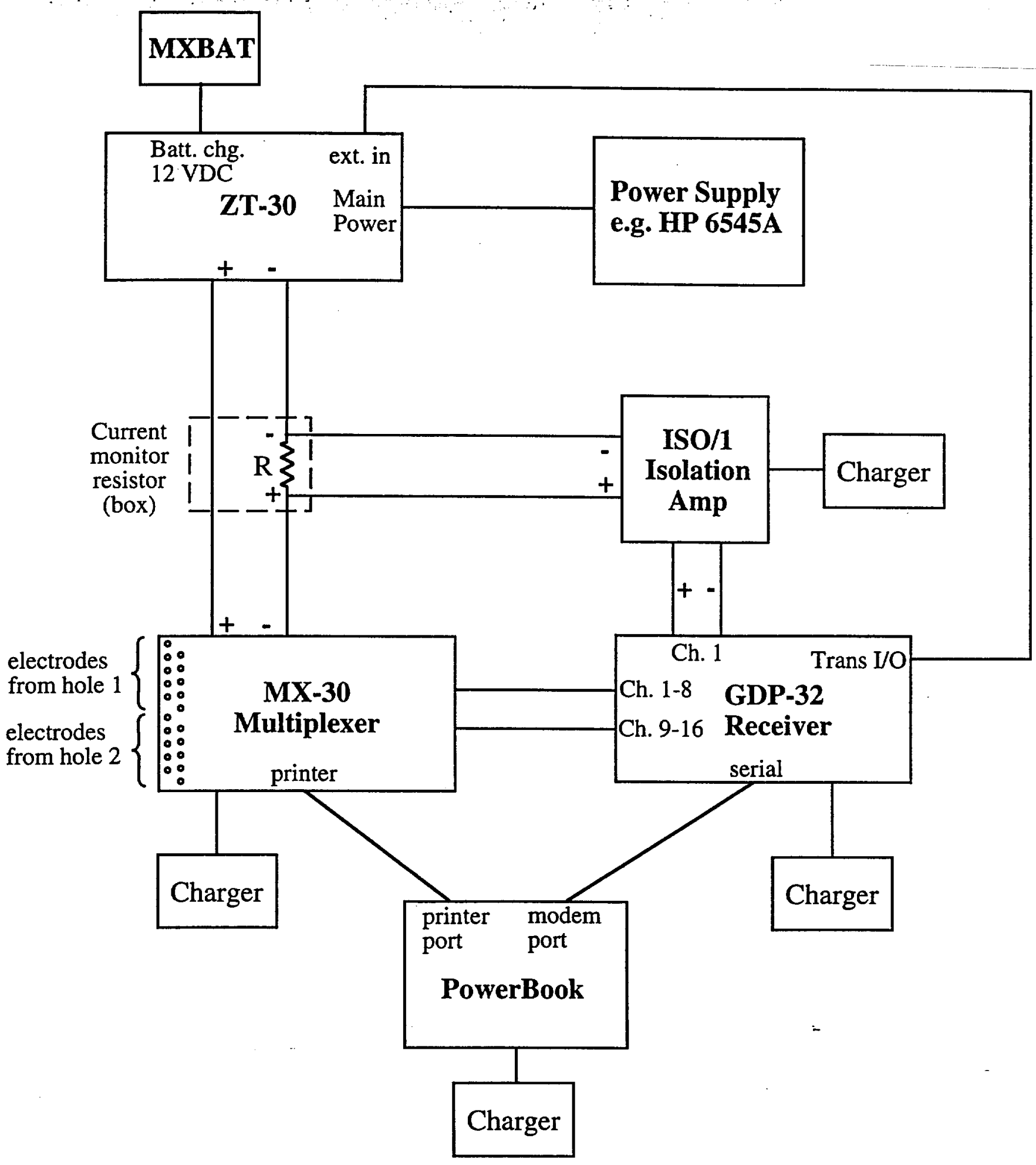

Figure 8. Block diagram for ERT data collection system used at Richmond Field Station 


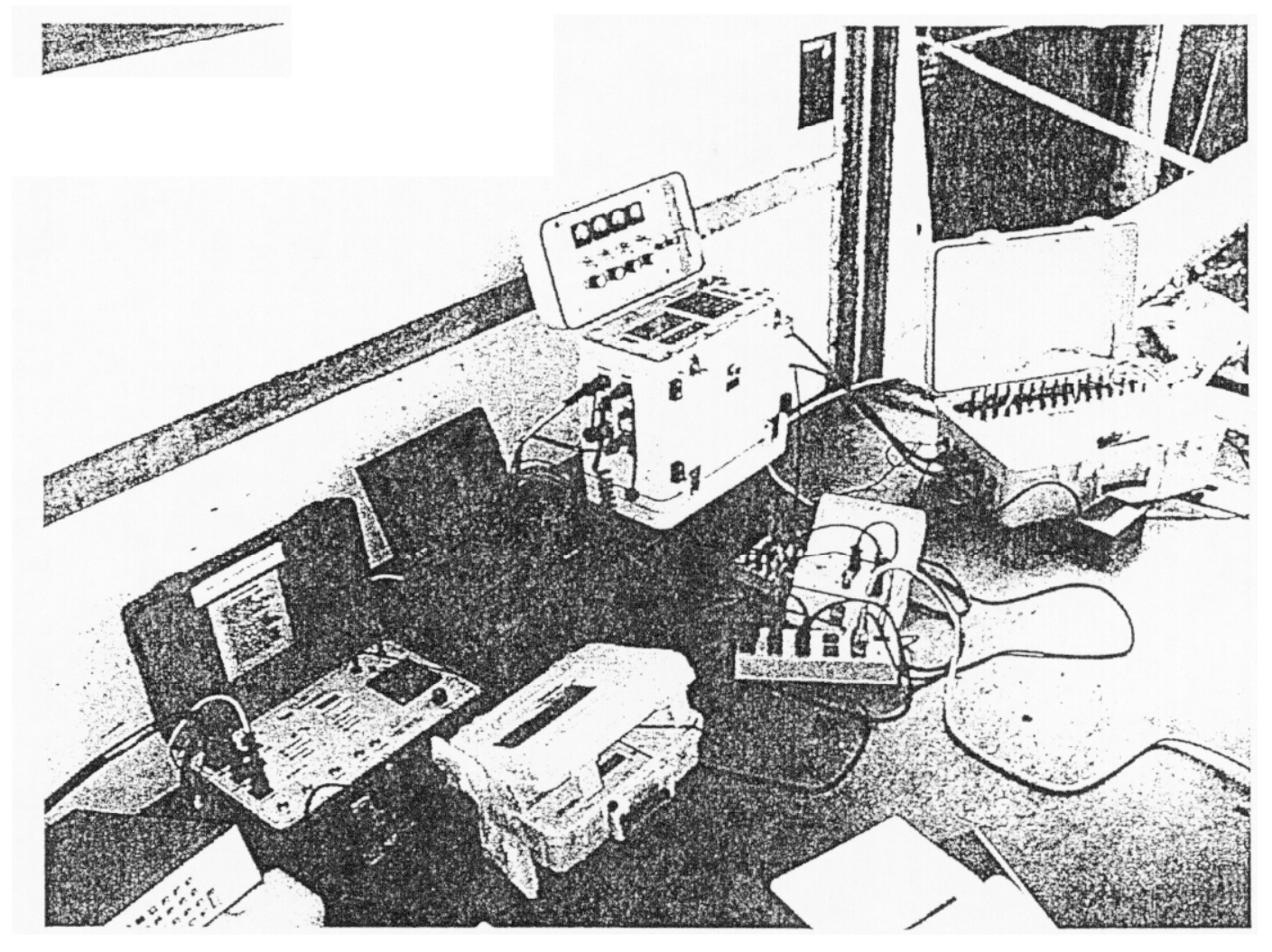

Figure 9. ERT data acquisition system deployed in rental truck at Richmond Field Station 

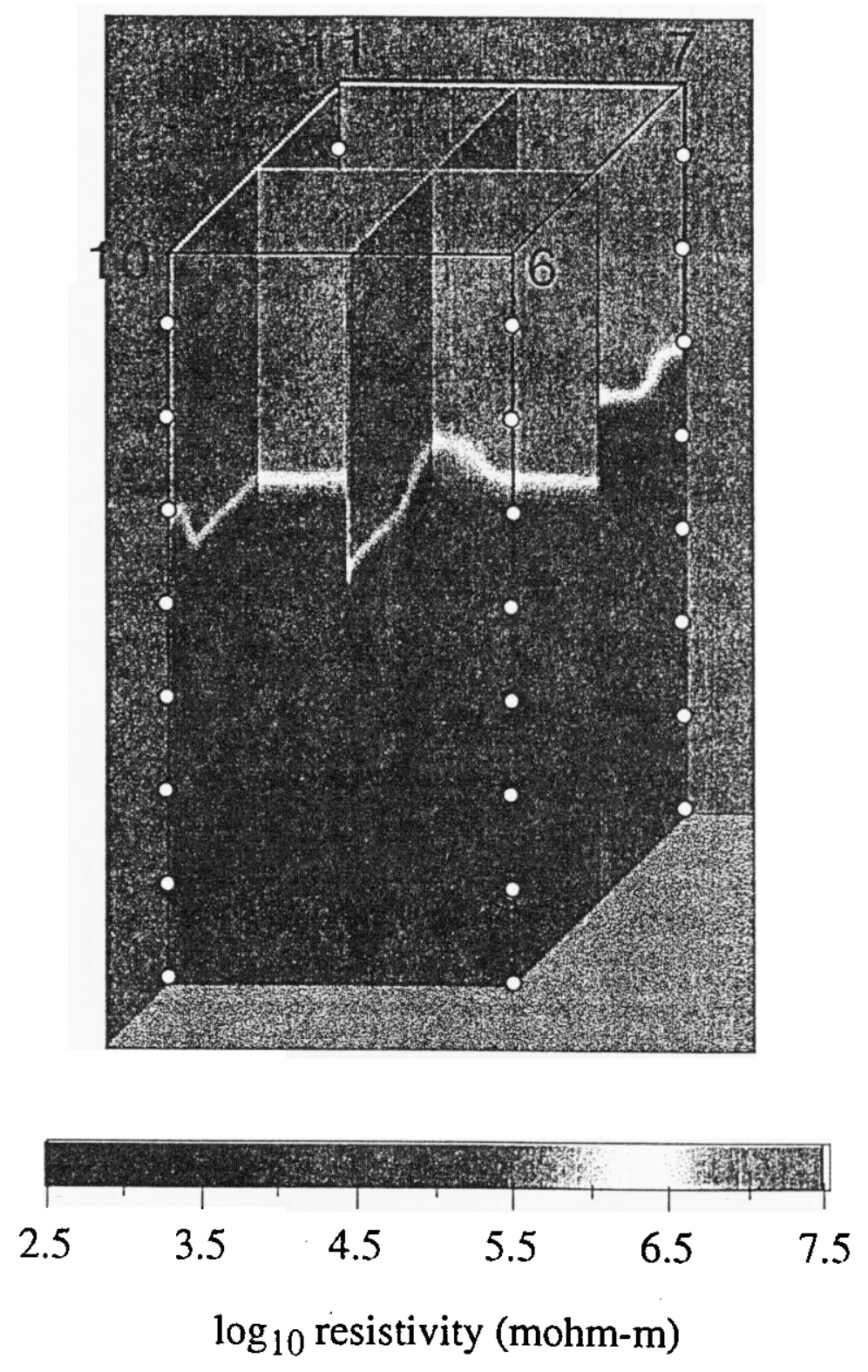

Figure 10. A 3d background image of the inner box at the Richmond Field Station 
plane 10,11
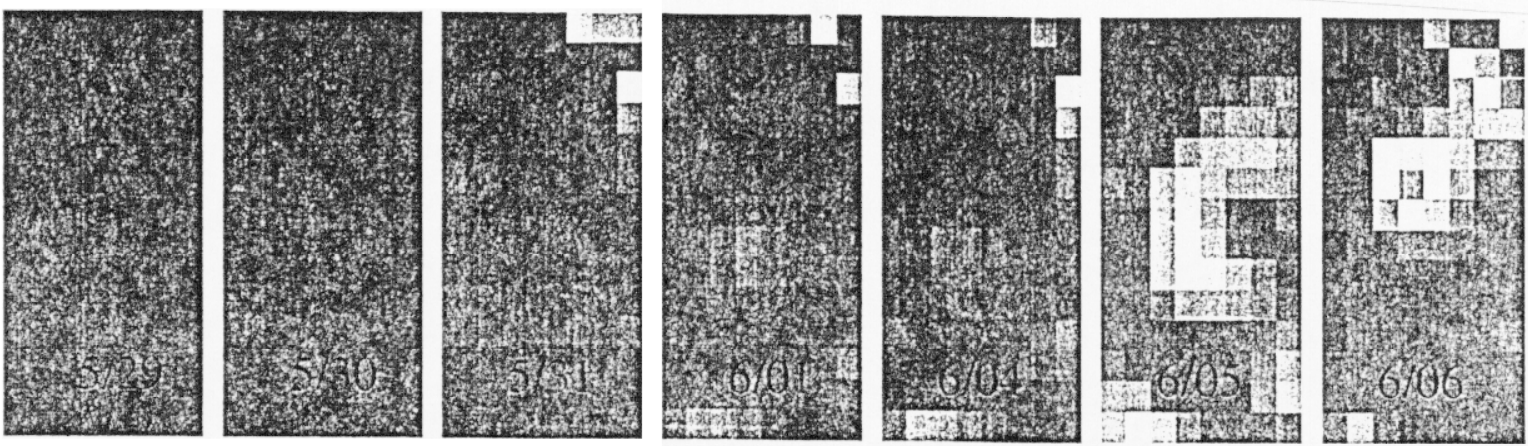

plane 7,6
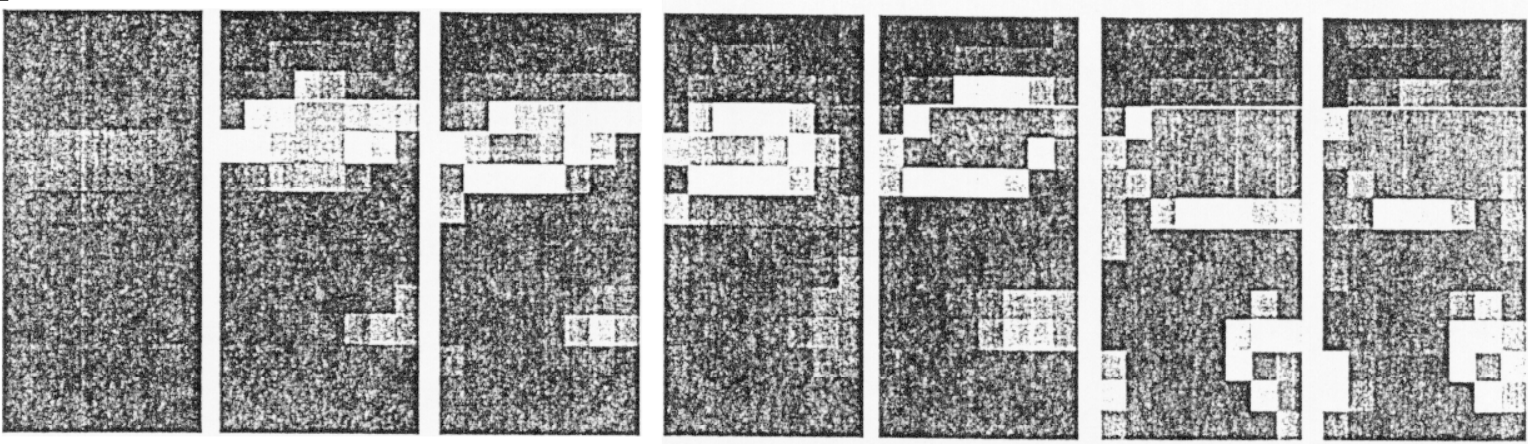

plane 10,6
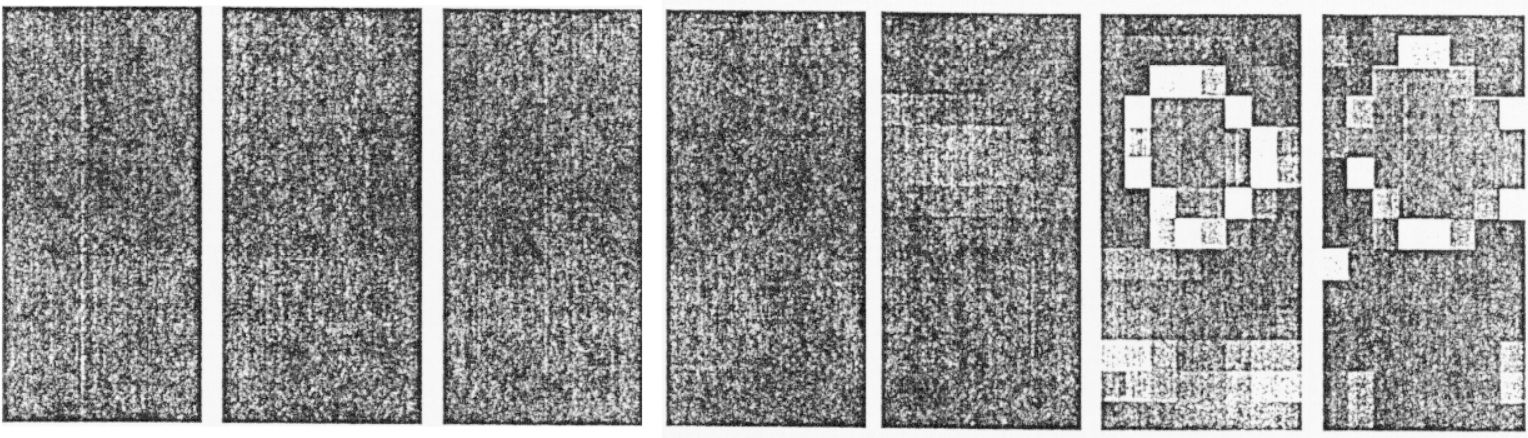

plane 7,11
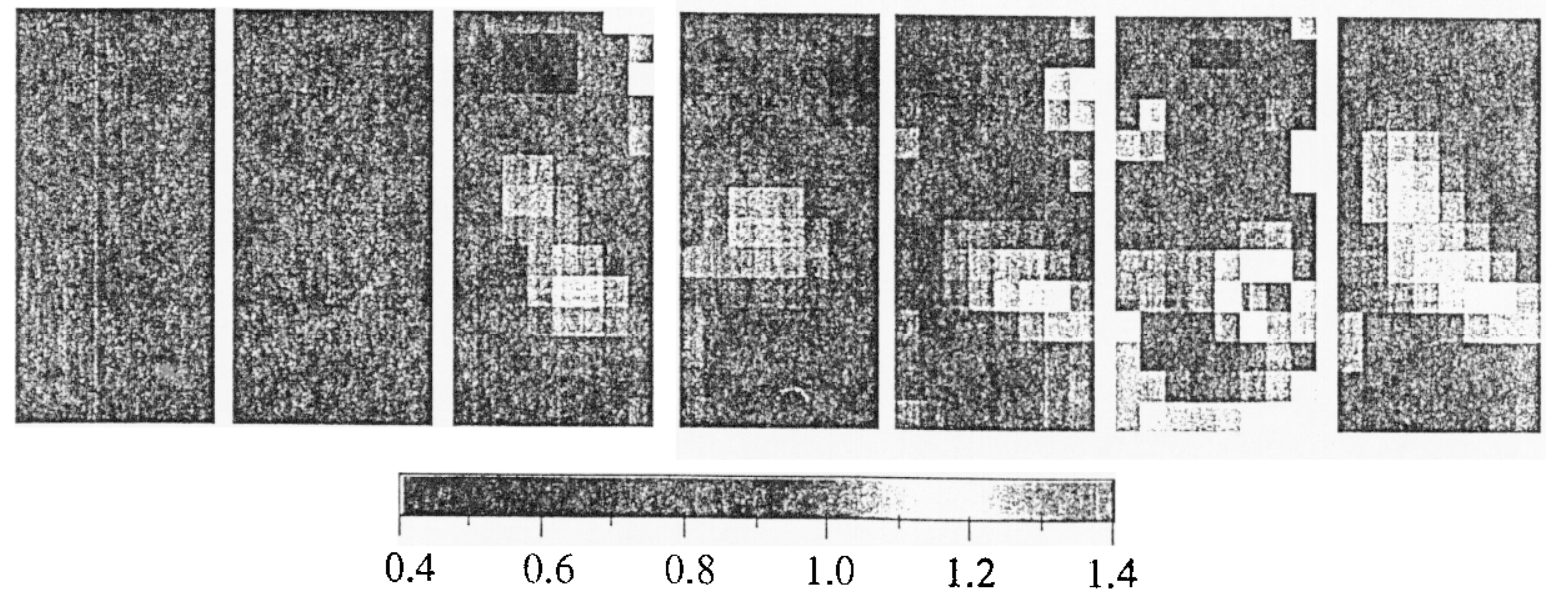

Figure 11. A sequence of images showing the time history for the outer planes of the inner box during water infiltration 
diagonal plane $10,17,7$
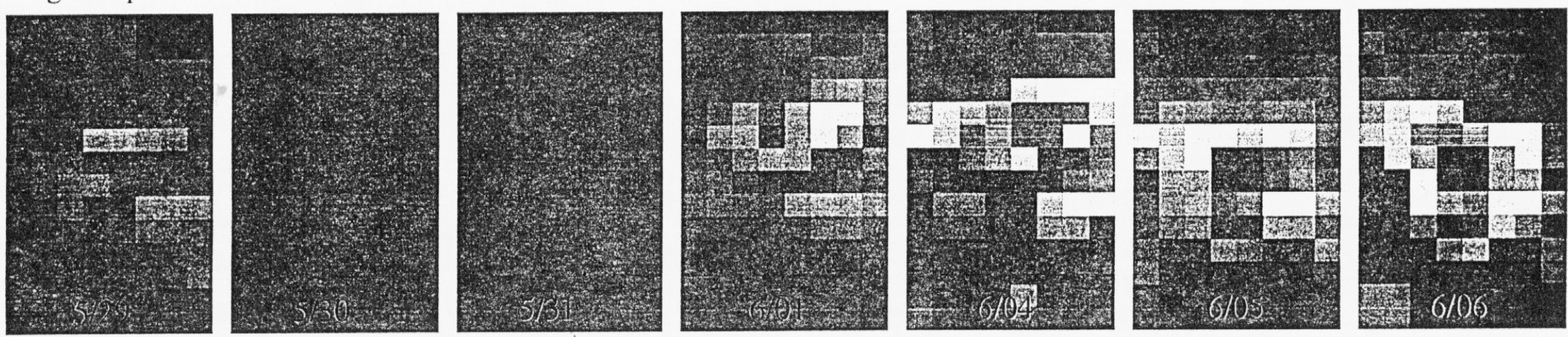

diagonal plane 11,17,6
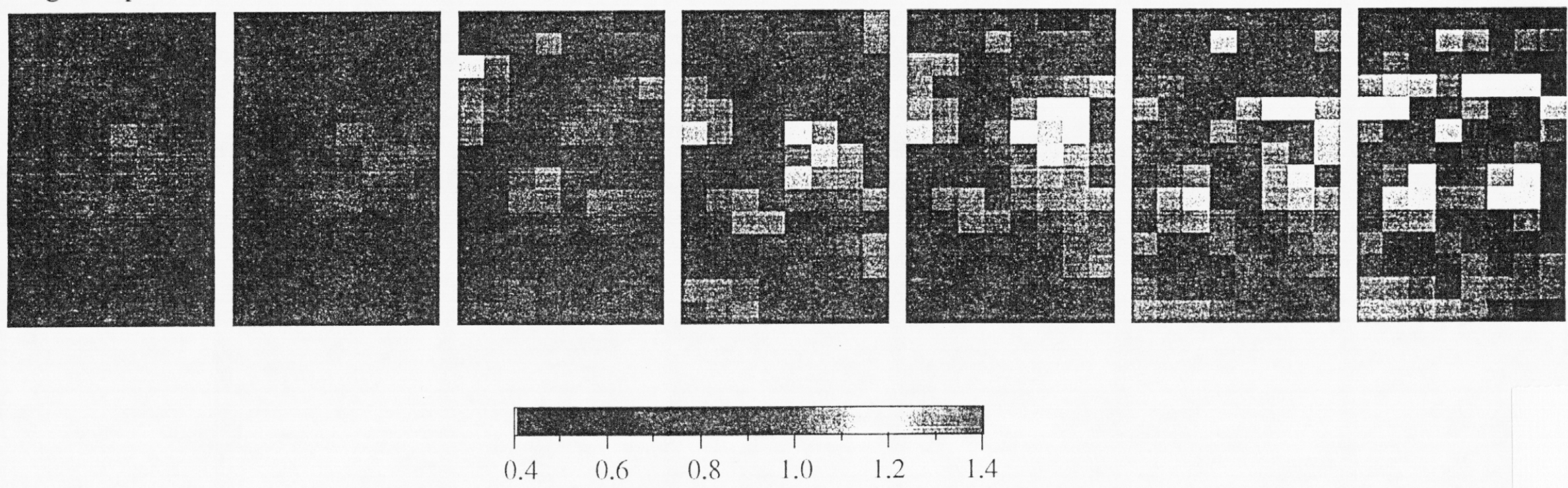

Figure 12. A sequence of images showing the time history for the diagonal planes of the inner box during water infilltration 


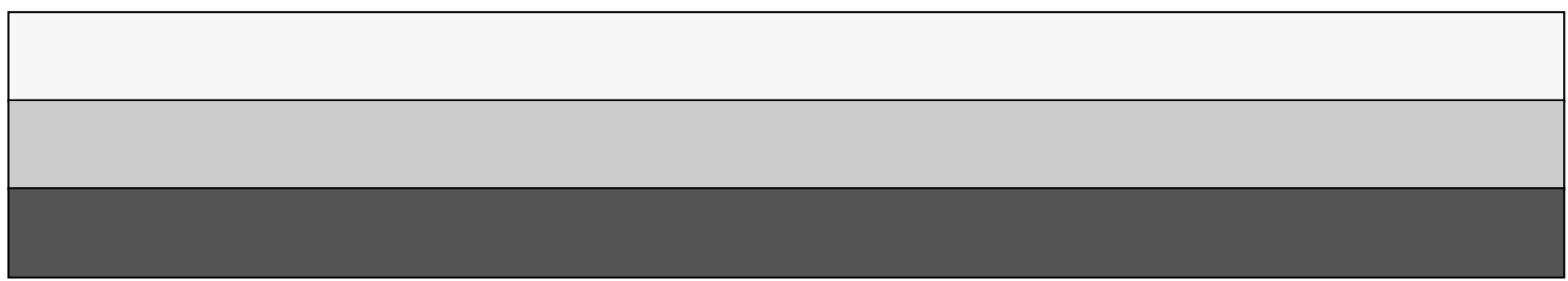

